Article

\title{
Microwave Assisted Synthesis of Some New Thiazolopyrimidine, Thiazolodipyrimidine and Thiazolopyrimidothiazolopyrimidine Derivatives with Potential Antioxidant and Antimicrobial Activity
}

\author{
Mohamed M. Youssef ${ }^{1, \dagger, *}$ and Mahmoud A. Amin ${ }^{2, \dagger}$ \\ 1 Chemistry Department, Faculty of Science, Cairo University, Cairo 12613, Egypt \\ 2 Chemistry Department, Faculty of Science, Suez Canal University, Ismailia 41522, Egypt \\ + Current address: Chemistry Department, Faculty of Science, Taif University, Taif 21974, Saudi Arabia. \\ * Author to whom correspondence should be addressed; E-Mail: mmmyousef@yahoo.com; \\ Tel.: +966-596-072-593.
}

Received: 7 July 2012; in revised form: 3 August 2012 / Accepted: 7 August 2012 /

Published: 13 August 2012

\begin{abstract}
Biginelli reaction of ethyl acetoacetate, thiourea and the appropriate aromatic aldehyde was used to produce ethyl 4-aryl-6-methyl-2-thioxo-1,2,3,4-tetrahydropyrimidine-5-carboxylates, that reacted with bromomalononitrile to give ethyl 3-amino-5aryl-2-cyano-7-methyl-5H-thiazolo[3,2-a]pyrimidine-6-carboxylates rather than the isomeric $7 H$-thiazolo[3,2-a]pyrimidines. Thiazolopyrimidine derivatives reacted with carbon disulphide to yield ethyl 9-aryl-7-methyl-2,4-dithioxo-2,3,4,9-tetrahydro- $1 \mathrm{H}$ thiazolo[3,2- $a: 4,5-d$ ] dipyrimidine-8-carboxylates, that reacted with phenacyl bromide to produce ethyl 8-methyl-10-(4-methoxyphenyl)-3-substituted-5-thioxo-2(un)subatituted$10 H$-thiazolo[3",2": 1',2']pyrimido[4',5':4,5] thiazolo[3,2-a]pyrimidine-9-carboxylates. The aforementioned reactions were carried out using both conventional chemical methods and with the assistance of microwave irradaition. Comparison between both methods showed that the microwave assisted method is preferable because of the time reduction and yield improvements achieved. The new compounds were tested for their biological activity as antioxidants, antibacterial or antifungal agents. Some of the new compounds were found to have moderate to good antioxidant and antimicrobial activities.
\end{abstract}


Keywords: biginelli reaction; 2-thioxopyrimidines; thiazolopyrimidines; thiazolo-dipyrimidines; thiazolopyrimidothiazolopyrimidines; antioxidant activity; antimicrobial activity

\section{Introduction}

Thiazolopyrimidenes have been of interest due to their ability to inhibit 2-methylerythritol-2,4cyclodiphosphate synthase [1]. They have been also used as analgesic and antiparkinsonian agents [2], modulators of Transient Receptor Potential Vanilloid-receptor 1 (TRPV1) [3], anticancer agents [4-6], pesticides [7], phosphate inhibitors [8,9], acetylcholinesterase inhibitors [10] and antimicrobial susbtances [11-13].

The microwave technique has several advantages over conventional methods of synthesis. Reduced reaction times [14-17], less effects on the environment and better reaction yields are some of the common advantages of using microwave irradaition. In the present research, we used both the microwave technique as well as conventional methods to prepare some thiazolopyrimidine, thiazolodipyrimidine and thiazolopyrimidothiazolopyrimidines derivatives with expected biological activity.

\section{Results and Discussion}

\subsection{Chemistry}

Prompted by the aforesaid biological and medicinal activities, samples of differently substituted thiazolopyrimidines and thiazolodipyrimidines were synthesized, using both conventional chemical methods and microwave irradiation assistance. The reaction of the precursors, ethyl 4-aryl-6-methyl-2thioxo-1,2,3,4-tetrahydropyrimidine-5-carboxylates $\mathbf{1 a - d}$, with some bifunctional reagents seems to be a facile and convenient route for the synthesis of such targets. The newly synthesized compounds were tested for their antioxidant and antimicrobial activities.

The precursor pyrimidine derivatives 1a-d were prepared by the acid catalyzed condensation of ternary mixtures of aromatic aldehydes, ethyl acetoacetate and thiourea in ethanol containing a catalytic amount of hydrochloric acid, commonly known as Biginelli reaction [18-20] (Scheme 1). Compounds 1a-d, prepared by Biginelli's method, showed correct values of elemental analyses, as well as compatible spectroscopic data.

Treating each of 1a-d with bromomalononitrile (2) in an ethanol solution containing potassium hydroxide yielded in each case a single product which could in principle be formulated to be either the $5 H$-thiazolo[3,2-a]pyrimidine structure 3 or the isomeric $7 H$-thiazolo[3,2-a]pyrimidine structure 4 (Scheme 1). Our preference for structure 3 over structure 4 was firstly based on comparison of the ${ }^{1} \mathrm{H}-\mathrm{NMR}$ spectral data for compounds $\mathbf{1}$ and $\mathbf{3}$. Thus, the ${ }^{1} \mathrm{H}-\mathrm{NMR}$ spectrum of $\mathbf{3 b}$ showed, in addition to the ethyl ester, methoxy, aromatic and $\mathrm{NH}_{2}$ proton signals, a singlet $(3 \mathrm{H})$ at $\delta 2.30 \mathrm{ppm}$ assigned to the $\mathrm{CH}_{3}$ protons and a singlet $(1 \mathrm{H})$ at $\delta 6.31$ assigned to the pyrimidine $\mathrm{H}-5$. The appearance of the $\mathrm{CH}_{3}$ proton signal of $\mathbf{3 b}$ in the same position as that for the $\mathrm{CH}_{3}$ proton signal in $\mathbf{1 b}$, and also the downfield shift for the pyrimidine H-5 in $\mathbf{3 b}$ compared with the pyrimidine $\mathrm{H}-4$ in $\mathbf{1 b}$, which appeared at $\delta=5.12 \mathrm{ppm}$, indicates that the moiety around H-5 in $\mathbf{3 b}$ differs from that around 
Finally, compound $\mathbf{5 b}$ reacted with $\alpha$-halocarbonyl compounds, namely chloroacetone, phenacyl bromide and 3-chloropentane-2,4-dione (compounds $\mathbf{6 a - c}$ ), respectively, by heating in ethanolic potassium hydoxide solution to produce the respective thiazolo[3",2":1',2']pyrimido[4',5':4,5]thiazolo[3,2-a]pyrimidine-9-carboxylate derivatives 7a-c (Scheme 1). Besides giving correct elemental analyses and compatible spectral data (see the Experimental), structure 7 was assigned to the reaction products based on the behaviour of a similar structure reported in literature by Hafez et al. [21].

Our research group has recently [22-25] been interested in performing synthesis of some heterocyclic compounds under environmentally friendly, time saving microwave-assisted conditions. Accordingly, we re-synthesized the previously described compounds 1a-d, 3a-d, 5a-d, and 7a-c under microwave conditions, aiming to increase reaction yields and reduce the reaction times. The results of these preparations indicated that reaction yields were increased by $17-23 \%$ compared to the conventional conditions. Reaction times were also significantly reduced. Table 1 summarizes the benefits of using microwave conditions for the synthesis of the above-mentioned compounds.

Table 1. Comparison between traditional methods and microwave assisted methods of synthesis of compounds $\mathbf{1 a}-\mathbf{d}, \mathbf{3 a}-\mathbf{d}, \mathbf{5 a}-\mathbf{d}$, and $\mathbf{7 a}-\mathbf{c}$.

\begin{tabular}{ccccc}
\hline \multirow{2}{*}{$\begin{array}{c}\text { Compound } \\
\text { no. }\end{array}$} & \multicolumn{2}{c}{ Reaction Yield \% } & \multicolumn{2}{c}{ Reaction Time } \\
\cline { 2 - 5 } & Microwave & $\begin{array}{c}\text { Conventional } \\
\text { Method }\end{array}$ & Microwave & $\begin{array}{c}\text { Conventional } \\
\text { Method }\end{array}$ \\
\hline 1a & 82 & 55 & $5 \mathrm{~min}$ & $3 \mathrm{~h}$ \\
$\mathbf{1 b}$ & 87 & 58 & $5 \mathrm{~min}$ & $3 \mathrm{~h}$ \\
$\mathbf{1 c}$ & 70 & 42 & $5 \mathrm{~min}$ & $3 \mathrm{~h}$ \\
$\mathbf{1 d}$ & 62 & 35 & $5 \mathrm{~min}$ & $3 \mathrm{~h}$ \\
$\mathbf{3 a}$ & 81 & 56 & $10 \mathrm{~min}$ & Overnight \\
$\mathbf{3 b}$ & 85 & 48 & $10 \mathrm{~min}$ & Overnight \\
$\mathbf{3 c}$ & 85 & 53 & $10 \mathrm{~min}$ & Overnight \\
$\mathbf{3 d}$ & 68 & 40 & $10 \mathrm{~min}$ & Overnight \\
$\mathbf{5 a}$ & 82 & 50 & $15 \mathrm{~min}$ & $8 \mathrm{~h}$ \\
$\mathbf{5 b}$ & 80 & 53 & $15 \mathrm{~min}$ & $8 \mathrm{~h}$ \\
$\mathbf{5 c}$ & 79 & 44 & $15 \mathrm{~min}$ & $8 \mathrm{~h}$ \\
$\mathbf{5 d}$ & 69 & 37 & $15 \mathrm{~min}$ & $8 \mathrm{~h}$ \\
$\mathbf{7 a}$ & 74 & 43 & $5 \mathrm{~min}$ & $3 \mathrm{~h}$ \\
$\mathbf{7 b}$ & 88 & 52 & $5 \mathrm{~min}$ & $3 \mathrm{~h}$ \\
$\mathbf{7 c}$ & 83 & 58 & $5 \mathrm{~min}$ & $3 \mathrm{~h}$ \\
\hline
\end{tabular}

\subsection{Biological Evaluation}

\subsubsection{Antioxidant Screening}

The newly synthesized compounds were tested for antioxidant activity as reflected in their ability to inhibit lipid peroxidation in rat brain and kidney homogenates and rat erythrocyte hemolysis. The pro-oxidant activities of the aforementioned compounds were assessed by their effects on bleomycininduced DNA damage. Table 2 shows the antioxidant assays by erythrocyte hemolysis, which reveals that compounds $\mathbf{3 a}$ and $\mathbf{3 b}$ showed interesting antioxidant activity in the lipid peroxidation assays and considerable inhibitory activity in the hemolysis assay. Compounds $\mathbf{3 c}, \mathbf{3 d}, \mathbf{7 a}, \mathbf{7 b}$ and $\mathbf{7 c}$ showed 
moderate antioxidant and inhibitory activity. Table 3 shows the antioxidant assay by ABTS method. Compounds 3a, 3b, 3c and 3d showed potent antioxidant activity.

Table 2. Antioxidant assays by erythrocyte hemolysis $(\mathrm{A} / \mathrm{B} \times 100)$.

\begin{tabular}{ccc}
\hline Compounds & Absorbance of samples (A) & Hemolysis (\%) \\
\hline $\begin{array}{c}\text { Complete hemolysis } \\
\text { with distilled water (B) }\end{array}$ & 0.660 & - \\
\hline Ascorbic acid & 0.026 & 3.93 \\
$\mathbf{1 a}$ & 0.082 & 10.33 \\
$\mathbf{1 b}$ & 0.075 & 9.12 \\
$\mathbf{1 c}$ & 0.090 & 13.01 \\
$\mathbf{1 d}$ & 0.092 & 14.12 \\
$\mathbf{3 a}$ & 0.035 & 5.22 \\
$\mathbf{3 b}$ & 0.031 & 4.68 \\
$\mathbf{3 c}$ & 0.045 & 6.92 \\
$\mathbf{3 d}$ & 0.051 & 8.02 \\
$\mathbf{5 a}$ & 0.115 & 21.60 \\
$\mathbf{5 b}$ & 0.112 & 19.25 \\
$\mathbf{5 c}$ & 0.132 & 24.07 \\
$\mathbf{5 d}$ & 0.130 & 23.12 \\
$\mathbf{7 a}$ & 0.042 & 6.36 \\
$\mathbf{7 b}$ & 0.045 & 6.81 \\
$\mathbf{7 c}$ & 0.043 & 6.51 \\
\hline
\end{tabular}

Table 3. Antioxidant assays by ABTS method [Abs. (control) - Abs.(test)/Abs. (control) $\times 100$ ]

\begin{tabular}{ccc}
\hline Compounds & Absorbance of sample & Inhibition (\%) \\
\hline ABTS control & 0.54 & 0 \\
Ascorbic acid & 0.06 & 88.8 \\
$\mathbf{1 a}$ & 0.20 & 63.0 \\
$\mathbf{1 b}$ & 0.23 & 57.4 \\
$\mathbf{1 c}$ & 0.29 & 46.3 \\
$\mathbf{1 d}$ & 0.28 & 48.1 \\
$\mathbf{3 a}$ & 0.10 & 81.5 \\
$\mathbf{3 b}$ & 0.12 & 77.7 \\
$\mathbf{3 c}$ & 0.15 & 72.2 \\
$\mathbf{3 d}$ & 0.13 & 75.9 \\
$\mathbf{5 a}$ & 0.45 & 16.6 \\
$\mathbf{5 b}$ & 0.42 & 22.2 \\
$\mathbf{5 c}$ & 0.48 & 11.1 \\
$\mathbf{5 d}$ & 0.43 & 20.3 \\
$\mathbf{7 a}$ & 0.17 & 68.5 \\
$\mathbf{7 b}$ & 0.19 & 64.8 \\
$\mathbf{7 c}$ & 0.16 & 70.3 \\
\hline
\end{tabular}

All compounds have been tested on bleomycin-dependent DNA damage. The results, shown in Table 4, indicate that compounds 3a-d may have some protective activity towards DNA from the damage induced by bleomycin. 
Table 4. Assays for bleomycin-dependent DNA damage.

\begin{tabular}{cc}
\hline Compound & Absorbance of Samples \\
\hline Ascorbic acid & 0.020 \\
3a & 0.026 \\
3b & 0.029 \\
3c & 0.037 \\
3d & 0.033 \\
\hline
\end{tabular}

\subsubsection{Antimicrobial Evaluation}

The newly synthesized heterocyclic compounds listed in Table 4 were tested for their antimicrobial activity against the following microorganisms: Escherichia coli, Pseudomonas putida, Bacillus subtilis, Streptococcus lactis, Aspergillus niger, Penicillium sp. and Candida albicans. The preliminary screening of the investigated compounds was performed using the filter paper disc-diffusion method. The most active compounds were $\mathbf{1 a}, \mathbf{1 b}, \mathbf{3 a}, \mathbf{3 b}, \mathbf{5 a}$, and $\mathbf{5 b}$, which showed moderate to slight inhibitory action towards the microorganisms. The rest of compounds showed slight to no sensitivity at all to the tested organisms, and the results are summarized in Table 5.

Table 5. Antimicrobial activities of the newly synthesized compounds.

\begin{tabular}{|c|c|c|c|c|c|c|c|}
\hline \multirow{3}{*}{$\begin{array}{c}\text { Compd. } \\
\text { No. }\end{array}$} & \multicolumn{7}{|c|}{ Inhibition zone (mm) } \\
\hline & \multicolumn{2}{|c|}{ Gram-negative } & \multicolumn{2}{|c|}{ Gram-positive } & \multicolumn{3}{|c|}{ Fungi Yeast } \\
\hline & E. coli & P. putida & B. subtilis & S. lactis & A. niger & $P$. sp. & C. albicans \\
\hline $1 \mathrm{a}$ & 12 & 8 & 6 & 8 & 5 & 5 & 0 \\
\hline $1 \mathrm{~b}$ & 14 & 9 & 6 & 7 & 4 & 2 & 0 \\
\hline $1 \mathrm{c}$ & 6 & 3 & 0 & 0 & 2 & 2 & 0 \\
\hline 1d & 3 & 2 & 0 & 0 & 0 & 0 & 0 \\
\hline $3 a$ & 15 & 11 & 9 & 6 & 7 & 5 & 0 \\
\hline $\mathbf{3 b}$ & 12 & 7 & 7 & 5 & 7 & 5 & 0 \\
\hline $3 \mathbf{c}$ & 0 & 0 & 0 & 0 & 0 & 0 & 0 \\
\hline 3d & 2 & 2 & 0 & 0 & 0 & 0 & 0 \\
\hline $5 \mathbf{a}$ & 10 & 7 & 8 & 6 & 4 & 3 & \\
\hline $5 \mathbf{b}$ & 11 & 8 & 9 & 6 & 5 & 2 & \\
\hline $5 c$ & 4 & 2 & 0 & 0 & 0 & 0 & 0 \\
\hline $5 d$ & 3 & 0 & 0 & 0 & 0 & 0 & 0 \\
\hline $7 a$ & 0 & 0 & 0 & 0 & 0 & 0 & 0 \\
\hline $7 b$ & 0 & 0 & 0 & 0 & 0 & 0 & 0 \\
\hline $7 \mathrm{c}$ & 0 & 0 & 0 & 0 & 0 & 0 & 0 \\
\hline Chloram-phenicol $^{\circledR}$ & 22 & 21 & 18 & 19 & 20 & 12 & 0 \\
\hline Ampicillin $^{\circledR}$ & 24 & 20 & 19 & 22 & 24 & 14 & 14 \\
\hline
\end{tabular}

E. coli $=$ Escherichia coli $;$ P. putida $=$ Pseudomonas putida B. subtilis $=$ Bacillus subtilis;

S. lactis $=$ Streptococcus lactis; A. niger $=$ Aspergillus niger; $P$. sp. = Penicillium sp.; C. albicans $=$ Candida albicans; The sensitivity of microorganisms to the tested compounds is identified in the following manner *: Highly sensitive = Inhibition zone: 15-20 mm; Moderately sensitive $=$ Inhibition zone: $10-15 \mathrm{~mm}$; Slightly sensitive $=$ Inhibition zone: $1-10 \mathrm{~mm}$; Not sensitive $=$ Inhibition zone: $0 \mathrm{~mm}$; * each result represents the average of triplicate readings. 


\section{Experimental}

\subsection{General}

Melting points were determined in open glass capillaries on a Gallenkamp melting point apparatus and are uncorrected. IR spectra ( $\mathrm{KBr}$ discs) were recorded on a Shimadzu FTIR-8201PC Spectrophotometer. ${ }^{1} \mathrm{H}-\mathrm{NMR}$ and ${ }^{13} \mathrm{C}$-NMR spectra were recorded on a Varian Mercury $300 \mathrm{MHz}$ and a Varian Gemini $200 \mathrm{MHz}$ spectrometers using TMS as an internal standard and DMSO- $d_{6}$, and as a solvent. Chemical shifts were expressed as $\delta$ (ppm) units. Mass spectra were recorded on a Shimadzu GCMS-QP1000EX instrument using an inlet type sample injection at $70 \mathrm{eV}$. The Microanalytical Center of Cairo University performed the microanalyses. Microwave reactions were performed with a Millstone Organic Synthesis Unit (MicroSYNTH with touch control terminal) with a continuous focused microwave power delivery system in a pressure glass vessel $(10 \mathrm{~mL})$ sealed with a septum under magnetic stirring. The temperature of the reaction mixture was monitored using a calibrated infrared temperature control under the reaction vessel, and control of the pressure was performed with a pressure sensor connected to the septum of the vessel.

\subsubsection{Ethyl 4-aryl-6-methyl-2-thioxo-1,2,3,4-tetrahydropyrimidine-5-carboxylates 1a-d}

Method A: A solution of thiourea $(0.76 \mathrm{~g}, 0.01 \mathrm{~mol})$, ethyl acetoacetate $(1.30 \mathrm{~g}, 0.01 \mathrm{~mol})$ and the appropriate aromatic aldehyde $(0.01 \mathrm{~mol})$ in ethanol $(50 \mathrm{~mL})$ in the presence of conc. $\mathrm{HCl}(5 \mathrm{~mL})$ was heated under reflux for $3 \mathrm{~h}$. The reaction mixture was then allowed to stand at room temperature overnight whereby the solid precipitate so-formed was collected by filtration, washed with ethanol and crystallized from ethanol.

Method B: The same reactants of Method $A$ were heated in microwave oven at $140{ }^{\circ} \mathrm{C}$ for $5 \mathrm{~min}$. The reaction mixture was treated in a similar manner to Method $A$ to obtain compounds $\mathbf{1 a}-\mathbf{d}$.

Ethyl 4-(4-(dimethylamino)phenyl)-6-methyl-2-thioxo-1,2,3,4-tetrahydropyrimidine-5-carboxylate (1a) was obtained as pale green crystals, m.p. $201{ }^{\circ} \mathrm{C} .{ }^{1} \mathrm{H}-\mathrm{NMR}: \delta(\mathrm{ppm}) 1.10\left(\mathrm{t}, 3 \mathrm{H}, \mathrm{CH}_{3}, J=4 \mathrm{~Hz}\right), 2.26$ (s, 3H, $\left.\mathrm{CH}_{3}\right), 2.87$ (s, 6H, N( $\left.\left.\mathrm{CH}_{3}\right)_{2}\right), 3.97$ (q, 2H, $\mathrm{CH}_{2}, J=4 \mathrm{~Hz}$ ), 5.02 (s, 1H, pyrimidine H-4), 6.65 (d, 2H, Ar-H, $J=5 \mathrm{~Hz}$ ), 7.00 (d, 2H, Ar-H, $J=5 \mathrm{~Hz}$ ), 9.55 (s, 1H, NH, $\mathrm{D}_{2} \mathrm{O}$ exchangeable) and 10.23 (s, 1H, NH, $\mathrm{D}_{2} \mathrm{O}$ exchangeable). ${ }^{13} \mathrm{C}-\mathrm{NMR}: \delta$ (ppm) $14.1\left(\mathrm{CH}_{3}\right), 17.2\left(\mathrm{CH}_{3}\right), 53.5$ (pyrimidine $\left.\mathrm{C}-4\right)$, $59.5\left(\mathrm{~N}\left(\mathrm{CH}_{3}\right)_{2}\right), 67.3\left(\mathrm{CH}_{2}\right), 101.2,112.2,127.1,131.2,144.4,150.0$ (aromatic carbons + pyrimidine C-5 and C-6), $165.3(\mathrm{C}=\mathrm{S})$ and $173.8(\mathrm{C}=\mathrm{O})$. IR $(\mathrm{KBr}) \mathrm{v}$ : 3268, $3188(\mathrm{NH}), 1718(\mathrm{C}=\mathrm{O}), 1605,1500 \mathrm{~cm}^{-1}$ (Aromatic $\mathrm{C}=\mathrm{C})$. MS (70 eV): $\left(\mathrm{M}^{+}\right) \mathrm{m} / \mathrm{z} 319$ (11.2\%). Anal. Calcd. for $\mathrm{C}_{16} \mathrm{H}_{20} \mathrm{~N}_{3} \mathrm{O}_{2} \mathrm{~S}(319.42)$ : C(60.16\%), H(6.63\%), N(13.16\%), S(10.04); Found: C(60.3\%), H(6.8\%), N(13.4\%), S(10.0\%).

Ethyl 4-(4-methoxyphenyl)-6-methyl-2-thioxo-1,2,3,4-tetrahydropyrimidine-5-carboxylate (1b) was obtained as yellow crystals, m.p. $144{ }^{\circ} \mathrm{C} .{ }^{1} \mathrm{H}-\mathrm{NMR}: \delta(\mathrm{ppm}) 1.22\left(\mathrm{t}, 3 \mathrm{H}, \mathrm{CH}_{3}, J=4 \mathrm{~Hz}\right.$ ), 2.26 (s, 3H, $\left.\mathrm{CH}_{3}\right), 3.25$ (s, 3H, $\left.\mathrm{OCH}_{3}\right), 3.95$ (q, 2H, $\left.\mathrm{CH}_{2}, J=4 \mathrm{~Hz}\right), 5.12$ (s, 1H, pyrimidine $\left.\mathrm{H}-4\right), 6.81$ (d, 2H, Ar-H, $J=6 \mathrm{~Hz}), 7.11(\mathrm{~d}, 2 \mathrm{H}, \mathrm{Ar}-\mathrm{H}, J=6 \mathrm{~Hz}), 9.50\left(\mathrm{~s}, 1 \mathrm{H}, \mathrm{NH}, \mathrm{D}_{2} \mathrm{O}\right.$ exchangeable) and $10.18(\mathrm{~s}, 1 \mathrm{H}, \mathrm{NH}$, $\mathrm{D}_{2} \mathrm{O}$ exchangeable). ${ }^{13} \mathrm{C}-\mathrm{NMR}: \delta(\mathrm{ppm}) 14.0\left(\mathrm{CH}_{3}\right), 17.4\left(\mathrm{CH}_{3}\right), 53.5$ (pyrimidine $\left.\mathrm{C}-4\right), 63.9\left(\mathrm{OCH}_{3}\right)$, $68.8\left(\mathrm{CH}_{2}\right), 103.4,113.1,129.7,134.2,145.9153 .2$ (aromatic carbons + pyrimidine C-5 and C-6), 
$165.6(\mathrm{C}=\mathrm{S})$ and $174.0(\mathrm{C}=\mathrm{O})$. IR $(\mathrm{KBr}) \mathrm{v}: 3272,3185(\mathrm{NH}), 1718(\mathrm{C}=\mathrm{O}), 1603,1506 \mathrm{~cm}^{-1}$ (Aromatic $\mathrm{C}=\mathrm{C})$. MS (70 eV): $\left(\mathrm{M}^{+}\right) \mathrm{m} / z 306$ (8.5\%). Anal. Calcd. for $\mathrm{C}_{15} \mathrm{H}_{18} \mathrm{~N}_{2} \mathrm{O}_{3} \mathrm{~S}$ (306.38): $\mathrm{C}(58.80 \%)$, H(5.92\%), N(9.14\%), S(10.47); Found: C(59.0\%), H(5.9\%), N(9.3\%), S(10.7\%).

Ethyl 4-(2-hydroxyphenyl)-6-methyl-2-thioxo-1,2,3,4-tetrahydropyrimidine-5-carboxylate (1c) was obtained as beige crystals, m.p. $235{ }^{\circ} \mathrm{C} .{ }^{1} \mathrm{H}-\mathrm{NMR}: \delta(\mathrm{ppm}) 1.18\left(\mathrm{t}, 3 \mathrm{H}, \mathrm{CH}_{3}, J=4 \mathrm{~Hz}\right), 2.19(\mathrm{~s}, 3 \mathrm{H}$, $\mathrm{CH}_{3}$ ), 3.95 (q, 2H, $\mathrm{CH}_{2}, J=4 \mathrm{~Hz}$ ), 5.10 (s, 1H, pyrimidine $\left.\mathrm{H}-4\right), 6.73-7.07$ (m, 4H, Ar-H), 8.40 (s, $1 \mathrm{H}, \mathrm{OH}, \mathrm{D}_{2} \mathrm{O}$ exchangeable), $9.55\left(\mathrm{~s}, 1 \mathrm{H}, \mathrm{NH}, \mathrm{D}_{2} \mathrm{O}\right.$ exchangeable) and $10.12\left(\mathrm{~s}, 1 \mathrm{H}, \mathrm{NH}, \mathrm{D}_{2} \mathrm{O}\right.$ exchangeable). ${ }^{13} \mathrm{C}-\mathrm{NMR}: \delta$ (ppm) $13.5\left(\mathrm{CH}_{3}\right), 16.8\left(\mathrm{CH}_{3}\right), 53.5$ (pyrimidine $\left.\mathrm{C}-4\right), 67.6\left(\mathrm{CH}_{2}\right), 102.7$, 112.6, 115.3, 122.0 127.7, 131.9, 144.6150 .9 (aromatic carbons + pyrimidine $\mathrm{C}-5$ and $\mathrm{C}-6$ ), 165.2 $(\mathrm{C}=\mathrm{S})$ and $172.6(\mathrm{C}=\mathrm{O})$. IR $(\mathrm{KBr})$ v: 3280-3080 (broad, $\mathrm{OH}+\mathrm{NH}), 1722(\mathrm{C}=\mathrm{O}), 1600,1501 \mathrm{~cm}^{-1}$ (Aromatic $\mathrm{C}=\mathrm{C})$. MS $(70 \mathrm{eV}):\left(\mathrm{M}^{+}\right) \mathrm{m} / \mathrm{z} 292$ (14.1\%). Anal. Calcd. for $\mathrm{C}_{14} \mathrm{H}_{16} \mathrm{~N}_{2} \mathrm{O}_{3} \mathrm{~S}(292.09)$ : $\mathrm{C}(57.52 \%), \mathrm{H}(5.52 \%), \mathrm{N}(9.58 \%), \mathrm{S}(10.97)$; Found: C(57.7\%), H(5.8\%), N(9.5\%), S(11.1\%).

Ethyl 4-(furan-2-yl)-6-methyl-2-thioxo-1,2,3,4-tetrahydropyrimidine-5-carboxylate (1d) was obtained as brown crystals, m.p. $176{ }^{\circ} \mathrm{C} .{ }^{1} \mathrm{H}-\mathrm{NMR}: \delta(\mathrm{ppm}) 1.25$ (t, 3H, $\left.\mathrm{CH}_{3}, J=4 \mathrm{~Hz}\right), 2.22\left(\mathrm{~s}, 3 \mathrm{H}, \mathrm{CH}_{3}\right), 4.20$ (q, $\left.2 \mathrm{H}, \mathrm{CH}_{2}, J=4 \mathrm{~Hz}\right), 5.23(\mathrm{~s}, 1 \mathrm{H}$, pyrimidine $\mathrm{H}-4), 6.44(\mathrm{~d}, 1 \mathrm{H}$, furan- $\mathrm{H}), 6.56(\mathrm{~m}, 1 \mathrm{H}$, furan- $\mathrm{H})$, $7.41\left(\mathrm{~d}, 1 \mathrm{H}\right.$, furan-H), $9.34\left(\mathrm{~s}, 1 \mathrm{H}, \mathrm{NH}, \mathrm{D}_{2} \mathrm{O}\right.$ exchangeable) and $10.20\left(\mathrm{~s}, 1 \mathrm{H}, \mathrm{NH}, \mathrm{D}_{2} \mathrm{O}\right.$ exchangeable). ${ }^{13} \mathrm{C}-\mathrm{NMR}$ : $\delta$ (ppm) $14.3\left(\mathrm{CH}_{3}\right), 17.5\left(\mathrm{CH}_{3}\right), 57.5$ (pyrimidine $\left.\mathrm{C}-4\right), 67.2\left(\mathrm{CH}_{2}\right), 106.2,110.9,143.1$, 145.3, 151.0152 .9 (furan carbons + pyrimidine $\mathrm{C}-5$ and $\mathrm{C}-6), 165.8(\mathrm{C}=\mathrm{S})$ and $173.0(\mathrm{C}=\mathrm{O}) . \mathrm{IR}(\mathrm{KBr})$ v: 3275, $3183(\mathrm{NH}), 1720(\mathrm{C}=\mathrm{O}), 1607,1500 \mathrm{~cm}^{-1}$ (aromatic $\left.\mathrm{C}=\mathrm{C}\right) . \mathrm{MS}(70 \mathrm{eV}):\left(\mathrm{M}^{+}\right) \mathrm{m} / z 266$ (6.3\%). Anal. Calcd. for $\mathrm{C}_{12} \mathrm{H}_{14} \mathrm{~N}_{2} \mathrm{O}_{3} \mathrm{~S}$ (266.32): $\mathrm{C}(54.12 \%), \mathrm{H}(5.30 \%), \mathrm{N}(10.52 \%), \mathrm{S}(12.04)$; Found: $\mathrm{C}(54.1 \%), \mathrm{H}(5.4 \%), \mathrm{N}(10.4 \%), \mathrm{S}(12.0 \%)$.

\subsubsection{Ethyl 3-amino-5-aryl-2-cyano-7-methyl-5H-thiazolo[3,2-a]pyrimidine-6-carboxylates (3a-d)}

Method A: To a warm ethanolic potassium hydroxide solution [prepared by dissolving $\mathrm{KOH}$ $(0.56 \mathrm{~g}, 0.01 \mathrm{~mol})$ in ethanol $(50 \mathrm{~mL})]$ of each of $1 \mathbf{a}-\mathbf{d}(0.01 \mathrm{~mol})$, bromomalononitrile $2(1.45 \mathrm{~g}$, $0.01 \mathrm{~mol}$ ) was added portion-wise with stirring. The reaction mixture was then left overnight at room temperature, whereby the solid product that separated upon dilution with water was filtered off and crystallized from the proper solvent.

Method B: The same reactants of method A were heated at $140{ }^{\circ} \mathrm{C}$ in microwave oven for $10 \mathrm{~min}$. The reaction mixture was treated in a similar manner to method A to obtain compounds $\mathbf{3 a}-\mathbf{d}$.

Ethyl 3-amino-2-cyano-5-(4-(dimethylamino)phenyl)-7-methyl-5H-thiazolo[3,2-a]pyrimidine-6carboxylate (3a) was crystallized from dil. dioxane as yellowish green crystals, m.p. $218{ }^{\circ} \mathrm{C}$. ${ }^{1} \mathrm{H}-\mathrm{NMR}: \delta(\mathrm{ppm}) 1.35$ (t, 3H, $\left.\mathrm{CH}_{3}, J=4 \mathrm{~Hz}\right), 2.34\left(\mathrm{~s}, 3 \mathrm{H}, \mathrm{CH}_{3}\right), 2.95\left(\mathrm{~s}, 6 \mathrm{H}, \mathrm{N}\left(\mathrm{CH}_{3}\right)_{2}\right), 4.15(\mathrm{q}, 2 \mathrm{H}$, $\mathrm{CH}_{2}, J=4 \mathrm{~Hz}$ ), 6.22 (s, 1H, pyrimidine H-5), 6.60 (d, 2H, Ar-H, $\left.J=5 \mathrm{~Hz}\right), 6.97$ (d, 2H, Ar-H, $J=5 \mathrm{~Hz}$ ) and $8.78\left(\mathrm{~s}, 2 \mathrm{H}, \mathrm{NH}_{2}, \mathrm{D}_{2} \mathrm{O}\right.$ exchangeable). ${ }^{13} \mathrm{C}-\mathrm{NMR}: \delta(\mathrm{ppm}) 14.5\left(\mathrm{CH}_{3}\right), 17.3\left(\mathrm{CH}_{3}\right), 58.8$ (pyrimidine C-5), $59.7\left(\mathrm{~N}\left(\mathrm{CH}_{3}\right)_{2}\right), 68.4\left(\mathrm{CH}_{2}\right), 107.3(\mathrm{CN}), 112.2,117.3,127.1,132.2,149.4,154.6$, 157.3, 158.1, 158.9 (aromatic carbons + pyrimidine C-6 and C-7, C-8a + thiazole C-2, C-3), and 171.6 $(\mathrm{C}=\mathrm{O})$. IR (KBr) v: 3310, $3244\left(\mathrm{NH}_{2}\right), 2217(\mathrm{CN}), 1724(\mathrm{C}=\mathrm{O}), 1605,1500 \mathrm{~cm}^{-1}$ (aromatic $\left.\mathrm{C}=\mathrm{C}\right) . \mathrm{MS}$ 
(70 eV): $\left(\mathrm{M}^{+}\right) \mathrm{m} / \mathrm{z} 383$ (7.3\%). Anal. Calcd. for $\mathrm{C}_{19} \mathrm{H}_{21} \mathrm{~N}_{5} \mathrm{O}_{2} \mathrm{~S}$ (383.14): $\mathrm{C}(59.51 \%), \mathrm{H}(5.52 \%)$, $\mathrm{N}(18.26 \%), \mathrm{S}(8.36)$; Found: C(59.6\%), H(5.8\%), N(18.3\%), S(8.3\%).

Ethyl 3-amino-2-cyano-5-(4-methoxyphenyl)-7-methyl-5H-thiazolo[3,2-a]pyrimidine-6-carboxylate (3b) was crystallized from ethanol as yellow crystals, m.p. $220{ }^{\circ} \mathrm{C} .{ }^{1} \mathrm{H}-\mathrm{NMR}: \delta(\mathrm{ppm}) 1.30(\mathrm{t}, 3 \mathrm{H}$, $\left.\mathrm{CH}_{3}, J=4 \mathrm{~Hz}\right), 2.30$ (s, 3H, $\left.\mathrm{CH}_{3}\right), 3.85$ (s, 3H, $\left.\mathrm{OCH}_{3}\right), 4.18$ (q, 2H, $\left.\mathrm{CH}_{2}, J=4 \mathrm{~Hz}\right), 6.31(\mathrm{~s}, 1 \mathrm{H}$, pyrimidine H-5), 6.80 (d, 2H, Ar-H, $J=6 \mathrm{~Hz}), 7.15(\mathrm{~d}, 2 \mathrm{H}, \mathrm{Ar}-\mathrm{H}, J=6 \mathrm{~Hz})$, and $8.40\left(\mathrm{~s}, 2 \mathrm{H}, \mathrm{NH}_{2}\right.$, $\mathrm{D}_{2} \mathrm{O}$ exchangeable). ${ }^{13} \mathrm{C}-\mathrm{NMR}: \delta(\mathrm{ppm}) 14.8\left(\mathrm{CH}_{3}\right), 17.4\left(\mathrm{CH}_{3}\right), 59.6$ (pyrimidine $\left.\mathrm{C}-5\right), 62.1\left(\mathrm{OCH}_{3}\right)$, $67.4\left(\mathrm{CH}_{2}\right), 108.1(\mathrm{CN}), 113.1,118.8,129.0,134.1,151.4,155.1,157.8,158.7,159.3$ (aromatic carbons + pyrimidine C-6 and C-7, C-8a + thiazole C-2, C-3), and $171.0(\mathrm{C}=\mathrm{O}) . \mathrm{IR}(\mathrm{KBr}) \mathrm{v}: 3300$, $3230\left(\mathrm{NH}_{2}\right), 2210(\mathrm{CN}), 1720(\mathrm{C}=\mathrm{O}), 1605,1500 \mathrm{~cm}^{-1}$ (aromatic $\left.\mathrm{C}=\mathrm{C}\right) . \mathrm{MS}(70 \mathrm{eV}):\left(\mathrm{M}^{+}\right) \mathrm{m} / z 370$ (8.1\%). Anal. Calcd. for $\mathrm{C}_{18} \mathrm{H}_{18} \mathrm{~N}_{4} \mathrm{O}_{3} \mathrm{~S}$ (370.43): $\mathrm{C}(58.36 \%), \mathrm{H}(4.90 \%), \mathrm{N}(15.12 \%), \mathrm{S}(8.66)$; Found: $\mathrm{C}(58.5 \%), \mathrm{H}(4.8 \%), \mathrm{N}(15.3 \%), \mathrm{S}(8.5 \%)$.

Ethyl 3-amino-2-cyano-5-(2-hydroxyphenyl)-7-methyl-5H-thiazolo[3,2-a]pyrimidine-6-carboxylate (3c) was crystallized from ethanol as yellow crystals, m.p. $277{ }^{\circ} \mathrm{C} .{ }^{1} \mathrm{H}-\mathrm{NMR}$ : $\delta(\mathrm{ppm}) 1.32\left(\mathrm{t}, 3 \mathrm{H}, \mathrm{CH}_{3}\right.$, $J=4 \mathrm{~Hz}$ ), 2.34 (s, 3H, $\left.\mathrm{CH}_{3}\right), 4.05$ (q, 2H, $\left.\mathrm{CH}_{2}, J=4 \mathrm{~Hz}\right), 6.24$ (s, 1H, pyrimidine $\left.\mathrm{H}-5\right), 6.80-7.18$ (m, $4 \mathrm{H}, \mathrm{Ar}-\mathrm{H}), 8.15$ (s, $1 \mathrm{H}, \mathrm{OH}, \mathrm{D}_{2} \mathrm{O}$ exchangeable) and $8.53\left(\mathrm{~s}, 2 \mathrm{H}, \mathrm{NH}_{2}, \mathrm{D}_{2} \mathrm{O}\right.$ exchangeable). ${ }^{13} \mathrm{C}-\mathrm{NMR}$ : $\delta(\mathrm{ppm}) 14.3\left(\mathrm{CH}_{3}\right), 17.1\left(\mathrm{CH}_{3}\right), 58.8$ (pyrimidine $\left.\mathrm{C}-5\right), 67.1\left(\mathrm{CH}_{2}\right), 107.3(\mathrm{CN}), 112.3,116.1,122.1$, 126.3, 131.3, 137.1, 152.1, 157.1, 157.9, 158.8, 159.5 (aromatic carbons + pyrimidine C-6 and C-7, $\mathrm{C}-8 \mathrm{a}+$ thiazole $\mathrm{C}-2, \mathrm{C}-3)$, and $173.0(\mathrm{C}=\mathrm{O}) . \mathrm{IR}(\mathrm{KBr})$ v: 3320-3118 (broad, $\left.\mathrm{OH}+\mathrm{NH}_{2}\right), 2210(\mathrm{CN})$, $1716(\mathrm{C}=\mathrm{O}), 1600,1500 \mathrm{~cm}^{-1}$ (aromatic $\left.\mathrm{C}=\mathrm{C}\right) . \mathrm{MS}(70 \mathrm{eV}):\left(\mathrm{M}^{+}\right) \mathrm{m} / z 356(12.5 \%)$. Anal. Calcd. for $\mathrm{C}_{17} \mathrm{H}_{16} \mathrm{~N}_{4} \mathrm{O}_{3} \mathrm{~S}$ (356.40): $\mathrm{C}(57.29 \%), \mathrm{H}(4.52 \%), \mathrm{N}(15.72 \%), \mathrm{S}(9.00)$; Found: $\mathrm{C}(57.5 \%), \mathrm{H}(4.6 \%)$, $\mathrm{N}(15.6 \%), \mathrm{S}(9.1 \%)$.

Ethyl 3-amino-2-cyano-5-(furan-2-yl)-7-methyl-5H-thiazolo[3,2-a]pyrimidine-6-carboxylate (3d) was crystallized from dioxane as brown crystals, m.p. $345{ }^{\circ} \mathrm{C} .{ }^{1} \mathrm{H}-\mathrm{NMR}: \delta(\mathrm{ppm}) 1.27\left(\mathrm{t}, 3 \mathrm{H}, \mathrm{CH}_{3}\right.$, $J=4 \mathrm{~Hz}), 2.21\left(\mathrm{~s}, 3 \mathrm{H}, \mathrm{CH}_{3}\right), 4.25\left(\mathrm{q}, 2 \mathrm{H}, \mathrm{CH}_{2}, J=4 \mathrm{~Hz}\right), 6.11(\mathrm{~s}, 1 \mathrm{H}$, pyrimidine $\mathrm{H}-5), 6.45(\mathrm{~d}, 1 \mathrm{H}$, furan-H), $6.61\left(\mathrm{~m}, 1 \mathrm{H}\right.$, furan-H), $7.43(\mathrm{~d}, 1 \mathrm{H}$, furan- $\mathrm{H})$ and $8.87\left(\mathrm{~s}, 2 \mathrm{H}, \mathrm{NH}_{2}, \mathrm{D}_{2} \mathrm{O}\right.$ exchangeable). ${ }^{13} \mathrm{C}-\mathrm{NMR}: \delta(\mathrm{ppm}) 14.7\left(\mathrm{CH}_{3}\right), 17.5\left(\mathrm{CH}_{3}\right), 62.3$ (pyrimidine $\left.\mathrm{C}-5\right), 67.4\left(\mathrm{CH}_{2}\right), 107.1(\mathrm{CN}), 112.6$, 114.1, 127.3, 135.1, 139.6, 143.1, 145.3, 151.0152 .9 (furan carbons + pyrimidine $\mathrm{C}-6$ and $\mathrm{C}-7$, $\mathrm{C}-8 \mathrm{a}+$ thiazole $\mathrm{C}-2, \mathrm{C}-3)$ and $173.3(\mathrm{C}=\mathrm{O}) . \mathrm{IR}(\mathrm{KBr})$ v: 3310, $3244\left(\mathrm{NH}_{2}\right), 2210(\mathrm{CN}), 1722(\mathrm{C}=\mathrm{O})$, 1605, $1510 \mathrm{~cm}^{-1}$ (aromatic $\left.\mathrm{C}=\mathrm{C}\right)$. MS $(70 \mathrm{eV}):\left(\mathrm{M}^{+}\right) \mathrm{m} / \mathrm{z} 330$ (4.8\%). Anal. Calcd. for $\mathrm{C}_{15} \mathrm{H}_{14} \mathrm{~N}_{4} \mathrm{O}_{3} \mathrm{~S}$ (330.36): C(54.53\%), H(4.27\%), N(16.96\%), S(9.71); Found: C(54.4\%), H(4.4\%), N(16.7\%), S(9.8\%).

3.1.3. Ethyl 9-aryl-7-methyl-2,4-dithioxo-2,3,4,9-tetrahydro-1H-thiazolo[3,2-a:4,5-d']dipyrimidine-8carboxylates $\mathbf{5 a}-\mathbf{d}$

Method A: Each of compounds 3a-d $(0.01 \mathrm{~mol})$ was heated under reflux with an excess of carbon disulphide $(10 \mathrm{~mL})$ for $8 \mathrm{~h}$. The reaction mixture was then cooled, and the solid that precipitated was filtered at the pump and crystallized from the proper solvent. 
Method B: The same reactants of method A were heated at $140{ }^{\circ} \mathrm{C}$ in microwave oven for 15 min. The reaction mixture was treated in a similar manner to method A to obtain compounds $\mathbf{5 a}-\mathbf{d}$.

Ethyl 9-(4-(dimethylamino)phenyl)-7-methyl-2,4-dithioxo-2,3,4,9-tetrahydro-1H-thiazolo-[3,2-a:4,5$d^{\prime}$ dipyrimidine-8-carboxylate (5a) was crystallized from dilute ethanol as grey crystals, m.p. $248{ }^{\circ} \mathrm{C}$. ${ }^{1} \mathrm{H}-\mathrm{NMR}: \delta(\mathrm{ppm}) 1.10\left(\mathrm{t}, 3 \mathrm{H}, \mathrm{CH}_{3}, J=4 \mathrm{~Hz}\right), 2.26\left(\mathrm{~s}, 3 \mathrm{H}, \mathrm{CH}_{3}\right), 2.84\left(\mathrm{~s}, 6 \mathrm{H}, \mathrm{N}\left(\mathrm{CH}_{3}\right)_{2}\right), 3.95(\mathrm{q}, 2 \mathrm{H}$, $\left.\mathrm{CH}_{2}, J=4 \mathrm{~Hz}\right), 5.88(\mathrm{~s}, 1 \mathrm{H}$, pyrimidine $\mathrm{H}-9), 6.60(\mathrm{~d}, 2 \mathrm{H}, \mathrm{Ar}-\mathrm{H}, J=5 \mathrm{~Hz}), 6.95(\mathrm{~d}, 2 \mathrm{H}, \mathrm{Ar}-\mathrm{H}$, $J=5 \mathrm{~Hz}), 11.35$ (s, 1H, NH, $\mathrm{D}_{2} \mathrm{O}$ exchangeable) and $12.12\left(\mathrm{~s}, 1 \mathrm{H}, \mathrm{NH}, \mathrm{D}_{2} \mathrm{O}\right.$ exchangeable). ${ }^{13} \mathrm{C}-\mathrm{NMR}$ : $\delta(\mathrm{ppm}) 14.2\left(\mathrm{CH}_{3}\right), 17.8\left(\mathrm{CH}_{3}\right), 53.5$ (pyrimidine $\left.\mathrm{C}-9\right), 59.6\left(\mathrm{~N}\left(\mathrm{CH}_{3}\right)_{2}\right), 67.3\left(\mathrm{CH}_{2}\right), 109.2,111.3$, 127.1, 132.2, 148.2, 154.3, 156.2 157.1, 161.9 (aromatic carbons + pyrimidine C-5a, C-7, $\mathrm{C}-8$ + thiazole C-4a, C-10a), $171.3(\mathrm{C}=\mathrm{S}), 175.1(\mathrm{C}=\mathrm{O})$ and $181.4(\mathrm{C}=\mathrm{S}) . \mathrm{IR}(\mathrm{KBr})$ v: 3305, 3200 $\left(\mathrm{NH}_{2}\right), 1712(\mathrm{C}=\mathrm{O}), 1605,1500 \mathrm{~cm}^{-1}$ (aromatic $\left.\mathrm{C}=\mathrm{C}\right)$. MS $(70 \mathrm{eV}):\left(\mathrm{M}^{+}\right) \mathrm{m} / z 459$ (3.2\%). Anal. Calcd. for $\mathrm{C}_{20} \mathrm{H}_{21} \mathrm{~N}_{5} \mathrm{O}_{2} \mathrm{~S}_{3}$ (459.61): $\mathrm{C}(52.26 \%), \mathrm{H}(4.61 \%), \mathrm{N}(15.24 \%), \mathrm{S}(20.93)$; Found: $\mathrm{C}(52.3 \%), \mathrm{H}(4.7 \%)$, $\mathrm{N}(15.5 \%), \mathrm{S}(20.8 \%)$.

Ethyl 9-(4-methoxyphenyl)-7-methyl-2,4-dithioxo-2,3,4,9-tetrahydro-1H-thiazolo[3,2-a:4,5-d']dipyrimidine-8-carboxylate (5b) was crystallized from ethanol as beige crystals, m.p. $243{ }^{\circ} \mathrm{C}$. ${ }^{1} \mathrm{H}-\mathrm{NMR}: \delta(\mathrm{ppm}) 1.13\left(\mathrm{t}, 3 \mathrm{H}, \mathrm{CH}_{3}, J=4 \mathrm{~Hz}\right), 2.32\left(\mathrm{~s}, 3 \mathrm{H}, \mathrm{CH}_{3}\right), 3.22\left(\mathrm{~s}, 3 \mathrm{H}, \mathrm{OCH}_{3}\right), 4.10(\mathrm{q}, 2 \mathrm{H}$, $\mathrm{CH}_{2}, J=4 \mathrm{~Hz}$ ), 5.95 (s, 1H, pyrimidine $\left.\mathrm{H}-9\right), 6.80$ (d, 2H, Ar-H, $\left.J=6 \mathrm{~Hz}\right), 7.12$ (d, 2H, Ar-H, $J=6 \mathrm{~Hz}), 11.30\left(\mathrm{~s}, 1 \mathrm{H}, \mathrm{NH}, \mathrm{D}_{2} \mathrm{O}\right.$ exchangeable) and 12.10 (s, $1 \mathrm{H}, \mathrm{NH}, \mathrm{D}_{2} \mathrm{O}$ exchangeable) ${ }^{13} \mathrm{C}-\mathrm{NMR}$ : $\delta(\mathrm{ppm}) 14.1\left(\mathrm{CH}_{3}\right), 18.6\left(\mathrm{CH}_{3}\right), 61.0$ (pyrimidine $\left.\mathrm{C}-9\right), 63.2\left(\mathrm{OCH}_{3}\right), 67.3\left(\mathrm{CH}_{2}\right), 110.4,114.6,130.0$, 133.8 149.8, 155.2, 156.4, 157.9, 162.2 (aromatic carbons + pyrimidine C-5a, C-7, C-8 + thiazole C-4a, $\mathrm{C}-10 \mathrm{a}), 171.1(\mathrm{C}=\mathrm{S}), 175.0(\mathrm{C}=\mathrm{O})$ and $181.5(\mathrm{C}=\mathrm{S})$. IR $(\mathrm{KBr})$ v: 3310, $3200(\mathrm{NH}), 1718(\mathrm{C}=\mathrm{O}), 1605$, $1500 \mathrm{~cm}^{-1}$ (aromatic $\left.\mathrm{C}=\mathrm{C}\right)$. MS $(70 \mathrm{eV}):\left(\mathrm{M}^{+}\right) \mathrm{m} / z 446(4.0 \%)$. Anal. Calcd. for $\mathrm{C}_{19} \mathrm{H}_{18} \mathrm{~N}_{4} \mathrm{O}_{3} \mathrm{~S}_{3}$ (446.57): C(51.10\%), H(4.06\%), N(12.55\%), S(21.54); Found: C(51.0\%), H(4.2\%), N(12.5\%), S(21.8\%).

Ethyl 9-(2-hydroxyphenyl)-7-methyl-2,4-dithioxo-2,3,4,9-tetrahydro-1H-thiazolo[3,2-a:4,5-d']dipyrimidine-8-carboxylate (5c) was crystallized from dioxane as pale green crystals, m.p. $295{ }^{\circ} \mathrm{C}$. ${ }^{1} \mathrm{H}-\mathrm{NMR}: \delta(\mathrm{ppm}) 1.28\left(\mathrm{t}, 3 \mathrm{H}, \mathrm{CH}_{3}, J=4 \mathrm{~Hz}\right), 2.25\left(\mathrm{~s}, 3 \mathrm{H}, \mathrm{CH}_{3}\right), 4.16$ (q, 2H, $\left.\mathrm{CH}_{2}, J=4 \mathrm{~Hz}\right), 6.11$ (s, $1 \mathrm{H}$, pyrimidine $\mathrm{H}-9), 6.80-7.20(\mathrm{~m}, 4 \mathrm{H}, \mathrm{Ar}-\mathrm{H}), 8.22\left(\mathrm{~s}, 1 \mathrm{H}, \mathrm{OH}, \mathrm{D}_{2} \mathrm{O}\right.$ exchangeable), $11.40(\mathrm{~s}, 1 \mathrm{H}$, $\mathrm{NH}, \mathrm{D}_{2} \mathrm{O}$ exchangeable) and $12.25\left(\mathrm{~s}, 1 \mathrm{H}, \mathrm{NH}, \mathrm{D}_{2} \mathrm{O}\right.$ exchangeable). ${ }^{13} \mathrm{C}-\mathrm{NMR}: \delta(\mathrm{ppm}) 14.3\left(\mathrm{CH}_{3}\right)$, $17.1\left(\mathrm{CH}_{3}\right), 58.8$ (pyrimidine C-5), $67.1\left(\mathrm{CH}_{2}\right), 107.3(\mathrm{CN}), 107.9,112.4,120.1,127.4,133.3,138.1$, 154.0, 158.1, 158.9, 159.4, 161.0 (aromatic carbons + pyrimidine C-5a, C-7, C-8 + thiazole C-4a, $\mathrm{C}-10 \mathrm{a}), 171.4(\mathrm{C}=\mathrm{S}), 174.8(\mathrm{C}=\mathrm{O})$ and $180.7(\mathrm{C}=\mathrm{S})$. IR $(\mathrm{KBr})$ v: 3300, $3230\left(\mathrm{NH}_{2}\right), 1710(\mathrm{C}=\mathrm{O})$, 1600, $1500 \mathrm{~cm}^{-1}$ (aromatic $\left.\mathrm{C}=\mathrm{C}\right)$. MS (70 eV): $\left(\mathrm{M}^{+}\right) \mathrm{m} / z 432(5.0 \%)$. Anal. Calcd. for $\mathrm{C}_{18} \mathrm{H}_{16} \mathrm{~N}_{4} \mathrm{O}_{3} \mathrm{~S}_{3}$ (432.54): C(49.98\%), H(3.73\%), N(12.95\%), S(22.24); Found: C(49.8\%), H(3.8\%), N(13.1\%), (22.1\%).

Ethyl 9-(furan-2-yl)-7-methyl-2,4-dithioxo-2,3,4,9-tetrahydro-1H-thiazolo[3,2-a:4,5-d'] dipyrimidine8 -carboxylate (5d) was crystallized from dioxane as dark green crystals, m.p. $255{ }^{\circ} \mathrm{C} .{ }^{1} \mathrm{H}-\mathrm{NMR}: \delta$ (ppm) $1.25\left(\mathrm{t}, 3 \mathrm{H}, \mathrm{CH}_{3}, J=4 \mathrm{~Hz}\right), 2.15\left(\mathrm{~s}, 3 \mathrm{H}, \mathrm{CH}_{3}\right), 4.00\left(\mathrm{q}, 2 \mathrm{H}, \mathrm{CH}_{2}, J=4 \mathrm{~Hz}\right), 6.11(\mathrm{~s}, 1 \mathrm{H}$, pyrimidine $\mathrm{H}-9), 6.51(\mathrm{~d}, 1 \mathrm{H}$, furan- $\mathrm{H}), 6.78(\mathrm{~m}, 1 \mathrm{H}$, furan- $\mathrm{H}), 7.55(\mathrm{~d}, 1 \mathrm{H}$, furan- $\mathrm{H}), 11.40(\mathrm{~s}, 1 \mathrm{H}$, $\mathrm{NH}, \mathrm{D}_{2} \mathrm{O}$ exchangeable) and $12.25\left(\mathrm{~s}, 1 \mathrm{H}, \mathrm{NH}, \mathrm{D}_{2} \mathrm{O}\right.$ exchangeable). ${ }^{13} \mathrm{C}-\mathrm{NMR}: \delta(\mathrm{ppm}) 14.5\left(\mathrm{CH}_{3}\right)$, $17.1\left(\mathrm{CH}_{3}\right), 62.1$ (pyrimidine C-9), $66.8\left(\mathrm{CH}_{2}\right), 106.6,110.0,123.3,134.8,138.7,142.7,144.9,151.4$ 
157.9 (furan carbons + pyrimidine C-5a, C-7, C-8 + thiazole C-4a, C-10a) $171.8(\mathrm{C}=\mathrm{S}), 173.9(\mathrm{C}=\mathrm{O})$ and $181.2(\mathrm{C}=\mathrm{S})$. IR $(\mathrm{KBr})$ v: 3310, $3244(2 \mathrm{NH}), 2210(\mathrm{CN}), 1722 \mathrm{~cm}^{-1}(\mathrm{C}=\mathrm{O}), 1605,1510$ (aromatic $\mathrm{C}=\mathrm{C})$. MS (70 eV): $\left(\mathrm{M}^{+}\right) \mathrm{m} / z 406$ (4.3\%). Anal. Calcd. for $\mathrm{C}_{16} \mathrm{H}_{14} \mathrm{~N}_{4} \mathrm{O}_{3} \mathrm{~S}_{3}$ (406.50): $\mathrm{C}(47.27 \%)$, $\mathrm{H}(3.47 \%), \mathrm{N}(13.78 \%), \mathrm{S}(23.66)$; Found: C(47.0\%), H(3.4\%), N(13.8\%), S(23.8\%).

3.1.4. Ethyl 8-methyl-10-(4-methoxyphenyl)-3-substituted-5-thioxo-2-(un)substituted-10H-thiazolo[3",2":1',2']pyrimido[4',5':4,5]thiazolo[3,2-a]pyrimidine-9-carboxylates 7a-c

Method A: A solution of $5 \mathbf{b}(4.46 \mathrm{~g}, 0.01 \mathrm{~mol})$ with each of chloroacetone $(0.92 \mathrm{~g}, 0.1 \mathrm{~mol})$, phenacyl bromide $(1.99 \mathrm{~g}, 0.01 \mathrm{~mol})$ or 3-chloropentane-2,4-dione $(1.34 \mathrm{~g}, 0.01 \mathrm{~mol})$ in ethanolic potassium hydroxide solution [prepared by dissolving $\mathrm{KOH}(0.56 \mathrm{~g}, 0.01 \mathrm{~mol})$ in ethanol $(50 \mathrm{~mL})$ ] was heated under reflux for $3 \mathrm{~h}$. A precipitate started to form on hot after $1 \mathrm{~h}$. After cooling, the produced precipitate was filtered off, dried and crystallized from dimethyl formamide.

Method B: The same reactants of method A were heated at $140{ }^{\circ} \mathrm{C}$ in microwave oven for $5 \mathrm{~min}$. The reaction mixture was treated in a similar manner to method $\mathrm{A}$ to obtain compounds $\mathbf{7 a}-\mathbf{c}$.

Ethyl 3,8-dimethyl-10-(4-methoxyphenyl)-5-thioxo-10H-thiazolo[3", 2": 1',2']pyrimido[4',5':4,5]thiazolo[3,2-a]pyrimidine-9-carboxylate (7a) was obtained as yellow crystals, m.p. $314{ }^{\circ} \mathrm{C}$. ${ }^{1} \mathrm{H}-\mathrm{NMR}: \delta(\mathrm{ppm}) 1.34\left(\mathrm{t}, 3 \mathrm{H}, \mathrm{CH}_{3}, J=4 \mathrm{~Hz}\right), 2.45\left(\mathrm{~s}, 3 \mathrm{H}, \mathrm{CH}_{3}\right), 3.11\left(\mathrm{~s}, 3 \mathrm{H}, \mathrm{CH}_{3}\right), 3.91(\mathrm{~s}, 3 \mathrm{H}$, $\left.\mathrm{OCH}_{3}\right), 4.53$ (q, 2H, $\left.\mathrm{CH}_{2}, J=4 \mathrm{~Hz}\right), 5.77$ (s, 1H, pyrimidine $\left.\mathrm{H}-10\right), 6.94$ (s, 1H, thiazole $\left.\mathrm{H}-2\right), 7.15$ (d, $2 \mathrm{H}, \mathrm{Ar}-\mathrm{H}, J=6 \mathrm{~Hz}), 7.68(\mathrm{~d}, 2 \mathrm{H}, \mathrm{Ar}-\mathrm{H}, J=6 \mathrm{~Hz}) .{ }^{13} \mathrm{C}-\mathrm{NMR}: \delta(\mathrm{ppm}) 14.7\left(\mathrm{CH}_{3}\right), 19.6\left(\mathrm{CH}_{3}\right), 23.3$ $\left(\mathrm{CH}_{3}\right), 58.2\left(\mathrm{OCH}_{3}\right), 63.1\left(\mathrm{CH}_{2}\right), 67.5$ (pyrimidine $\left.\mathrm{C}-10\right), 101.6,106.4,112.3,124.1,128.0,135.8$ 151.3, 155.0, 157.4, 158.3, 158.5, 160.1 (aromatic carbons + pyrimidine C-6a, C-7a, C-8, C-9, C-11a, $\mathrm{C}-12 \mathrm{a}+$ thiazole $\mathrm{C}-2, \mathrm{C}-3), 171.0(\mathrm{C}=\mathrm{O})$ and $182.5(\mathrm{C}=\mathrm{S})$. IR $(\mathrm{KBr}) \mathrm{v}: 1715(\mathrm{C}=\mathrm{O}), 1600,1508 \mathrm{~cm}^{-1}$ (Aromatic $\mathrm{C}=\mathrm{C}$ ). MS (70 eV): $\left(\mathrm{M}^{+}\right) \mathrm{m} / z 484$ (3.6\%). Anal. Calcd. for $\mathrm{C}_{22} \mathrm{H}_{20} \mathrm{~N}_{4} \mathrm{O}_{3} \mathrm{~S}_{3}(484.57)$ : C(54.52\%), H(4.16\%), N(11.56\%), S(19.85); Found: C(54.34\%), H(4.2\%), N(11.8\%), S(19.8\%).

Ethyl 8-methyl-10-(4-methoxyphenyl)-3-phenyl-5-thioxo-10H-thiazolo[3", 2": 1',2']pyrimido-[4',5':4,5]thiazolo[3,2-a]pyrimidine-9-carboxylate (7b) was obtained as orange crystals, m.p. $335{ }^{\circ} \mathrm{C} .{ }^{1} \mathrm{H}-\mathrm{NMR}$ : $\delta(\mathrm{ppm}) 1.41\left(\mathrm{t}, 3 \mathrm{H}, \mathrm{CH}_{3}, J=4 \mathrm{~Hz}\right), 3.17\left(\mathrm{~s}, 3 \mathrm{H}, \mathrm{CH}_{3}\right), 3.95\left(\mathrm{~s}, 3 \mathrm{H}, \mathrm{OCH}_{3}\right), 4.50\left(\mathrm{q}, 2 \mathrm{H}, \mathrm{CH}_{2}\right.$, $J=4 \mathrm{~Hz}), 5.75(\mathrm{~s}, 1 \mathrm{H}$, pyrimidine $\mathrm{H}-10), 7.04(\mathrm{~s}, 1 \mathrm{H}$, thiazole $\mathrm{H}-2), 7.22(\mathrm{~d}, 2 \mathrm{H}, \mathrm{Ar}-\mathrm{H}, J=6 \mathrm{~Hz})$, $7.41(\mathrm{~d}, 2 \mathrm{H}, \mathrm{Ar}-\mathrm{H}, J=6 \mathrm{~Hz}), 7.52-7.81(\mathrm{~m}, 5 \mathrm{H}, \mathrm{Ar}-\mathrm{H}) .{ }^{13} \mathrm{C}-\mathrm{NMR}: \delta(\mathrm{ppm}) 14.6\left(\mathrm{CH}_{3}\right), 24.7\left(\mathrm{CH}_{3}\right)$, $58.0\left(\mathrm{OCH}_{3}\right), 63.4\left(\mathrm{CH}_{2}\right), 67.2$ (pyrimidine $\left.\mathrm{C}-10\right)$, 103.2, 106.9, 112.8, 115.6, 124.9, 126.2, 128.0, 128.9, 129.3, 135.8, 152.2, 155.1, 157.2, 158.0, 160.4 (aromatic carbons + pyrimidine C-6a, C-7a, C-8, C-9, C-11a, C-12a + thiazole C-2, C-3), $170.7(\mathrm{C}=\mathrm{O})$ and $183.0(\mathrm{C}=\mathrm{S}) . \mathrm{IR}(\mathrm{KBr})$ v: $1718(\mathrm{C}=\mathrm{O}), 1600$, $1504 \mathrm{~cm}^{-1}$ (aromatic $\mathrm{C}=\mathrm{C}$ ). MS $(70 \mathrm{eV}):\left(\mathrm{M}^{+}\right) \mathrm{m} / z 546(2.3 \%)$. Anal. Calcd. for $\mathrm{C}_{27} \mathrm{H}_{22} \mathrm{~N}_{4} \mathrm{O}_{3} \mathrm{~S}_{3}$ (546.68): C(59.32\%), H(4.06\%), N(10.25\%), S(17.60); Found: C(59.2\%), H(4.2\%), N(10.6\%), S(17.8\%).

Ethyl 2-acetyl-3,8-dimethyl-10-(4-methoxyphenyl)-5-thioxo-10H-thiazolo[3",2": 1',2']pyrimido$\left[4^{\prime}, 5^{\prime}: 4,5\right]$ thiazolo[3,2-a]pyrimidine-9-carboxylate (7c) was obtained as yellow crystals, m.p. $308{ }^{\circ} \mathrm{C}$. ${ }^{1} \mathrm{H}-\mathrm{NMR}: \delta(\mathrm{ppm}) 1.35\left(\mathrm{t}, 3 \mathrm{H}, \mathrm{CH}_{3}, J=4 \mathrm{~Hz}\right), 2.47\left(\mathrm{~s}, 3 \mathrm{H}, \mathrm{CH}_{3}\right), 2.51\left(\mathrm{~s}, 3 \mathrm{H}, \mathrm{CH}_{3}\right), 3.10\left(\mathrm{~s}, 3 \mathrm{H}, \mathrm{CH}_{3}\right)$, $3.95\left(\mathrm{~s}, 3 \mathrm{H}, \mathrm{OCH}_{3}\right), 4.50\left(\mathrm{q}, 2 \mathrm{H}, \mathrm{CH}_{2}, J=4 \mathrm{~Hz}\right), 5.68$ (s, 1H, pyrimidine $\left.\mathrm{H}-10\right), 7.00$ (d, 2H, Ar-H, 
$J=6 \mathrm{~Hz}), 7.55(\mathrm{~d}, 2 \mathrm{H}, \mathrm{Ar}-\mathrm{H}, J=6 \mathrm{~Hz}) .{ }^{13} \mathrm{C}-\mathrm{NMR}: \delta(\mathrm{ppm}) 12.3\left(\mathrm{CH}_{3}\right), 14.5\left(\mathrm{CH}_{3}\right), 20.8\left(\mathrm{CH}_{3}\right), 25.3$ $\left(\mathrm{CH}_{3}\right), 58.0\left(\mathrm{OCH}_{3}\right), 63.1\left(\mathrm{CH}_{2}\right), 65.5$ (pyrimidine $\left.\mathrm{C}-10\right), 105.6,106.2,112.6,124.3,127.2,135.6$ 151.0, 154.3 155.6, 157.2, 158.1, 160.4 (aromatic carbons + pyrimidine C-6a, C-7a, C-8, C-9, C-11a, $\mathrm{C}-12 \mathrm{a}+$ thiazole $\mathrm{C}-2, \mathrm{C}-3), 170.4(\mathrm{C}=\mathrm{O})), 175.3(\mathrm{C}=\mathrm{O})$ and $182.5(\mathrm{C}=\mathrm{S}) . \mathrm{IR}(\mathrm{KBr})$ v: 1715, 1695 $(2 \mathrm{C}=\mathrm{O}), 1600,1508 \mathrm{~cm}^{-1}$ (aromatic $\left.\mathrm{C}=\mathrm{C}\right) . \mathrm{MS}(70 \mathrm{eV}):\left(\mathrm{M}^{+}\right) \mathrm{m} / z 526(5.5 \%)$. Anal. Calcd. for $\mathrm{C}_{24} \mathrm{H}_{22} \mathrm{~N}_{4} \mathrm{O}_{4} \mathrm{~S}_{3}$ (526.08): $\mathrm{C}(54.73 \%), \mathrm{H}(4.21 \%), \mathrm{N}(10.64 \%), \mathrm{S}(18.27)$; Found: $\mathrm{C}(54.5 \%), \mathrm{H}(4.3 \%)$, $\mathrm{N}(10.7 \%), \mathrm{S}(18.1 \%)$.

\subsection{Antioxidant Screening}

\subsubsection{Assay for Erythrocyte Hemolysis}

Blood was obtained from rats by cardiac puncture and collected in heparinized tubes. Erythrocytes were separated from plasma and the buffy coat and washed three times with 10 volumes of $0.15 \mathrm{M}$ $\mathrm{NaCl}$. During the last washing, the erythrocytes were centrifuged at 2,500 rpm for $10 \mathrm{~min}$ to obtain a constantly packed cell preparation. Erythrocyte hemolysis was mediated by peroxyl radicals in this assay system [26]. A 10\% suspension of erythrocytes in $\mathrm{pH} 7.4$ phosphate-buffered saline (PBS) was added to the same volume of $200 \mathrm{mM}$ 2,2'-azobis(2-amidinopropane)dihydrochloride (AAPH) solution (in PBS) containing samples to be tested at different concentrations. The reaction mixture was shaken gently while being incubated at $37^{\circ} \mathrm{C}$ for $24 \mathrm{~h}$. The reaction mixture was then removed, diluted with eight volumes of PBS and centrifuged at 2,500 rpm for $10 \mathrm{~min}$. The absorbance A of the supernatant was read at $540 \mathrm{~nm}$. Similarly, the reaction mixture was treated with eight volumes of distilled water to achieve complete hemolysis, and the absorbance B of the supernatant obtained after centrifugation was measured at $540 \mathrm{~nm}$. The percentage hemolysis was calculated by the equation $(1-\mathrm{A} / \mathrm{B}) \times 100 \%$. The data were expressed as mean standard deviation. L-Ascorbic was used as a positive control.

\subsubsection{Antioxidant Activity Screening Assay-ABTS Method}

For each of the investigated compounds $2 \mathrm{~mL}$ of 2,2'-azino-bis(3-ethylbenzthiazoline-6-sulphonic acid) (ABTS) solution $(60 \mathrm{mM})$ was added to $3 \mathrm{M} \mathrm{MnO}_{2}$ solution $(25 \mathrm{mg} / \mathrm{mL})$ all prepared in phosphate buffer $(\mathrm{pH} 7,0.1 \mathrm{M})$. The mixture was shaken, centrifuged, filtered, and the absorbance (Acontrol) of the resulting green-blue solution (ABTS radical solution) was adjusted at ca. 0.5 at $\lambda 734 \mathrm{~nm}$. Then, $50 \mu \mathrm{L}$ of $2 \mathrm{mM}$ solution of the test compound in spectroscopic grade $\mathrm{MeOH} /$ phosphate buffer (1:1) was added. The absorbance (Atest) was measured and the reduction in color intensity was expressed as $\%$ inhibition. The $\%$ inhibition for each compound is calculated from the following equation [27]:

$$
\% \text { Inhibition }=\frac{\text { Acontrol }- \text { Asample }}{\text { Acontrol }} \times 100
$$

Ascorbic acid (vitamin C) was used as standard antioxidant (positive control). Blank sample was run without $\mathrm{ABTS}$ and using $\mathrm{MeOH} /$ phosphate buffer (1:1) instead of sample. Negative control sample was run with $\mathrm{MeOH} /$ phosphate buffer (1:1) instead of tested compound. 


\subsubsection{Bleomycin-Dependent DNA Damage}

The assay was done according to Aeschlach et al. [28] with minor modifications. The reaction mixture $(0.5 \mathrm{~mL})$ contained DNA $(0.5 \mathrm{mg} / \mathrm{mL})$, bleomycin sulfate $(0.05 \mathrm{mg} / \mathrm{mL}), \mathrm{MgCl}_{2}(5 \mathrm{mM})$, $\mathrm{FeCl}_{3}(50 \mu \mathrm{M})$ and samples to be tested at different concentrations. L-Ascorbic acid was used as a positive control. The mixture was incubated at $37^{\circ} \mathrm{C}$ for $1 \mathrm{~h}$. The reaction was terminated by addition of $0.05 \mathrm{~mL}$ EDTA $(0.1 \mathrm{M})$. The color was developed by adding $0.5 \mathrm{~mL}$ thiobarbituric acid (TBA) (1\%, $\mathrm{w} / \mathrm{v})$ and $0.5 \mathrm{~mL} \mathrm{HCl}(25 \%, \mathrm{v} / \mathrm{v})$ followed by heating at $80{ }^{\circ} \mathrm{C}$ for $10 \mathrm{~min}$. After centrifugation, the extent of DNA damage was measured by increase in absorbance at $532 \mathrm{~nm}$.

\subsection{Antimicrobial Screening}

The newly synthesized heterocyclic compounds were tested for their antimicrobial activity against the following microorganisms: (a) Gram-negative: Escherichia coli and Pseudomonas putide; (b) Gram-positive: Bacillus subtilis and Streptococcus lactis; (c) Fungi: Aspergillus niger and Penicillium sp.; (d) Yeast: Candida albicans.

Media: Three types of specific media were used in this study:

Medium (1): For bacteria (Nutrient Medium), consisting of (g/L distilled water): peptone, 5 and meat extract, 3. $\mathrm{pH}$ was adjusted to 7.0.

Medium (2): For fungi (Potato Dextrose Medium), consisting of ( $\mathrm{g} / \mathrm{L}$ distilled water): Infusion from potatoes, 4 and $\mathrm{D}(+)$ glucose, 20 . $\mathrm{pH}$ was adjusted to 5.5 .

Medium (3): For yeast (Universal Medium), consisting of (g/L distilled water): yeast extract, 3; malt extract, 3 ; peptone, 5 and glucose, 10 . $\mathrm{pH}$ was adjusted to 5.5 .

For solid media, $2 \%$ agar was added. All media were sterilized at $121{ }^{\circ} \mathrm{C}$ for $20 \mathrm{~min}$.

Procedure (Filter Paper Diffusion Method) [29]

Proper concentrations of microbial suspensions were prepared from 1 (for bacteria to 3 (for yeast and fungi)-day-old liquid stock cultures incubated on a rotary shaker (100 rpm). In the case of fungi, 5 sterile glass beads were added to each culture flask. The mycelia were then subdivided by mechanical stirring at speed No. 1 for $30 \mathrm{~min}$. Turbidity of microorganisms was adjusted with a spectrophotometer at $350 \mathrm{~nm}$ to give an optical density of 1.0 Appropriate agar plates were aseptically surface inoculated uniformLy by a standard volume (ca. $1 \mathrm{~mL}$ ) of the microbial broth culture of the tested microorganism, namely E. coli, P. putide, B. subtilis, S. Lactis, A. Niger, Penicillium sp. and C. albicans.

Whatman No. 3 filter paper discs of $10 \mathrm{~mm}$ diameter were sterilized by autoclaving for $15 \mathrm{~min}$ at $121{ }^{\circ} \mathrm{C}$. Test compounds were dissolved in $80 \%$ ethyl alcohol to give final concentration of $5 \mu \mathrm{g} / \mathrm{mL}$. The sterile discs were impregnated with the test compounds $(5 \mu \mathrm{g} / \mathrm{disc})$. After the impregnated discs have been air dried, they were placed on the agar surface previously seeded with the organism to be tested. Discs were gently pressed with forceps to insure thorough contact with the media. Three discs were arranged per dish, suitably spaced apart, i.e., the discs should be separated by a distance that is equal to or slightly greater than the sum of the diameters of inhibition produced by each disc alone. Each test compound was conducted in triplicate. Plates were kept in the refrigerator at $5{ }^{\circ} \mathrm{C}$ for $1 \mathrm{~h}$ to 
permit good diffusion before transferring them to an incubator at $37{ }^{\circ} \mathrm{C}$ for $24 \mathrm{~h}$ for bacteria and at $30{ }^{\circ} \mathrm{C}$ for $72 \mathrm{~h}$ for yeast and fungi.

\section{Conclusions}

New thiazolopyrimidines have been synthesized using both conventional methods and microwave assisted conditions. The latter methods proved very efficient in reducing reaction times as well as increasing the overall yield of the reactions. The newly synthesized compounds were tested for their antioxidant and antimicrobial activities. Some compounds showed good or moderate antioxidant activity, whereas other compounds showed weak antimicrobial activity.

\section{Acknowledgements}

This research is financed by Al-Taif University, Al-Taif, Kingdom of Saudi Arabia. Project Number 1-432-1282.

\section{References}

1. Geist, J.G.; Lauw, S.; Illarinova, V.; Fischer, M.; Gwawert, T.; Rohdich, F.; Eisenreich, W.; Kaiser, J.; Groll, M.; Scheurer, C.; et al. Thiazolopyrimidine inhibitors of 2-methylerythritol 2,4-cyclodiphosphate synthase (IspF) from Mycobacterium tuberculosis and Plasmodium falciparum. ChemMedChem 2010, 5, 1092-1101.

2. Amr, A.-E.-G.; Maigali, S.S.; Abdulla, M.M. Synthesis, and analgesic and antiparkinsonian activities of thiopyrimidine, pyrane, pyrazoline, and thiazolopyrimidine derivatives from 2-chloro6-ethoxy-4-acetylpyridine. Monatsh. Chem. 2008, 139, 1409-1415.

3. Branstetter, B.J.; Breitenbucher, J.G.; Lebsack, A.D.; Xiao, W. Thiaolopyrimidine Modulators of TRPV1. U.S. Patent WO 005,303, 2008.

4. Flefel, E.E.; Salama, M.A.; El-Shahat, M.; El-Hashash, M.A.; El-Farargy, A.F. A novel synthesis of some new pyrimidine and thiazolopyrimidine derivatives for anticancer evaluation. Phosphorus Sulfur Silicon Relat. Elem. 2007, 182, 1739-1756.

5. Hammam, A.G.; Sharaf, M.A.; Abdel Hafez, N.A. Synthesis and anti-cancer activity of pyridine and thiazolopyrimidine derivatives using ethylpiperidone as a synthon. Indian J. Chem. 2001 40B, 213-221.

6. Said, M.; Abouzid, K.; Mouneer, A.; Ahmedy, A.; Osman, A.-M. Synthesis and biological evaluation of new thiazolopyrimidines. Arch. Pharm. Res. 2004, 27, 471-477.

7. Linder, W.; Brandes, W. Pesticidal Thiazolopyrimidine Derivatives. U.S. Patent 367,820, 1991.

8. Duval, R.; Kolb, S.; Braud, E.; Genest, D.; Garbay, C. Rapid discovery of triazolobenzylidenethiazolopyrimidines (TBTP) as CDC25 phosphatase inhibitors by parallel click chemistry and in situ screening. J. Comb. Chem. 2009, 11, 947-950.

9. Kolb, S.; Mondésert, O.; Goddard, M.L.; Jullien, D.; Villoutreix, B.O.; Ducommun, B.; Garbay, C.; Braud, E. Development of novel thiazolopyrimidines as CDC25B phosphatase inhibitors. ChemMedChem 2009, 4, 633-648. 
10. Zhi, H.; Chen, L.; Zhang, L.; Liu, S.; Wan, D.C.C.; Lin, H.; Hu, C. Design, synthesis, and biological evaluation of $5 H$-thiazolo[3,2-a]pyrimidine derivatives as a new type of acetylcholinesterase inhibitors. ARKIVOC 2008, xiii, 266-277.

11. Rashad, A.E.; Shamroukh, A.H.; Abdel-Megeid, R.E.; El-Sayed, W.A. Synthesis, reactions and antimicrobial evaluation of some polycondensed thieno-pyrimidine derivatives. Synth. Commun. 2010, 40, 1149-1160.

12. El-Emary, T.I.; Abdel-Mohsen, S.A. Synthesis and antimicrobial activity of some new 1,3-diphenylpyrazoles bearing pyrimidine, Pyrimidinethione, thiazolopyrimidine, triazolopyrimidine, thio- and alkylthiotriazolopyrimidinone moieties at the 4-position. Phosphorus Sulfur 2006, 181, 2459-2474.

13. Maddila, S.; Damu, G.L.V.; Oseghe, E.O.; Abafe, O.A.; Venakata, R.C.; Lavanya, P. Synthesis and biological studies of novel biphenyl-3,5-dihydro- $2 H$-thiazolo-pyrimidines derivatives. J. Korean Chem. Soc. 2012, 56, 334-340.

14. Sosnowski, M.; Skulski, L. Microwave-accelerated iodination of some aromatic amines, using urea-hydrogen peroxide addition compound (UHP) as the oxidant. Molecules 2002, 7, 867-870.

15. Gregg, B.; Golden, K.; Quinn, J. Indium(III) trifluoromethanesulfonate as an efficient catalyst for the deprotection of acetals and ketals. J. Org. Chem. 2007, 72, 5890-5893.

16. Lerebours, R.; Wolf, C. Palladium(II)-catalyzed conjugate addition of arylsiloxanes in water. Org. Lett. 2007, 9, 2737-2740.

17. Marion, N.; Gealageas, R.; Nolan, S. [(NHC)AuI]-catalyzed rearrangement of allylic acetates. Org. Lett. 2007, 9, 2653-2656.

18. Biginelli, P. Synthesis of 3,4-dihydropyrimidin-2(1H)-ones. Gazz. Chem. Ital. 1893, 23, 360-372.

19. Kappe, C.O. 100 Years of the Biginelli dihydropyridine synthesis. Tetrahedron 1993, 49, 6937-6963.

20. Akbas, E.; Aslanoglu, F. Studies on reactions of pyrimidine compounds. Microwave-assisted synthesis of 1,2,3,4-tetrahydro-2-thioxopyrimidine derivatives. Phosphorus Sulfur Silicon Relat. Elem. 2008, 183, 82-89.

21. Hafez, H.N.; Hussein, H.A.R.; El-Gazzar, A.B.A. Synthesis of substituted thieno-[2,3d]pyrimidine-2,4-dithiones and their S-glycoside analogues as potential antiviral and antibacterial agents. Eur. J Med. Chem. 2010, 45, 4026-4032.

22. Youssef, M.M.; Amin, M.A. Microwave assisted synthesis of some new heterocyclic spiro-derivatives with potential antimicrobial and antioxidant activity. Molecules 2010, 15, 8827-8840.

23. Faty, R.M.; Youssef, M.M.; Youssef, A.M.S. Microwave assisted synthesis and unusual coupling of some novel Pyrido[3,2-f][1,4]thiazepines. Molecules 2011, 16, 4549-4559.

24. Saad, H.A.; Youssef, M.M.; Mosselhi, M.A. Microwave assisted synthesis of some new fused 1,2,4-triazine bearing thiophene moiety of expected pharmacological activity. Molecules 2011, $16,4937-4957$.

25. Youssef, A.M.S.; Azab, M.E.; Youssef, M.M. Bromination and diazo-coupling of pyridinethiones; microwave assisted synthesis of isothiazolopyridine, pyridothiazine and pyridothiazepines. Molecules 2012, 17, 6930-6943. 
26. Morimoto, Y.; Tanaka, K.; Iwakiri, Y.; Tokuhiro, S.; Fukushima, S.; Takeuchi, Y. Protective effects of some neutral amino acids against hypotonic hemolysis. Biol. Pharm. Bull. 1995, 18, 1417-1422.

27. Lissi, E.; Modak, B.; Torres, R.; Escobar, J.; Urzua, A. Total antioxidant potential of resinousexudates from Heliotropium species, and a comparison of ABTS and DPPH methods. Free Radic. Res. 1999, 30, 471-477.

28. Aeschlach, R.; Loliger, J.; Scott, B.C.; Murciao, A.; Butler, J.; Halliwell, B.; Aruoma, O. Antioxidant actions of thymol, carvacrol, 6-gingerol, zingerone and hydroxytyrosol. Food Chem. Toxicol. 1994, 32, 31-36.

29. Coffen, D.L.; Korzan, D.G. Synthetic quinine analogs. III. Frangomeric and anchimeric processes in the preparation and reactions of $\alpha, \beta$-epoxy ketones. J. Org. Chem. 1971, 36, 390-395.

Sample Availability: Samples of the compounds are available from the authors.

(C) 2012 by the authors; licensee MDPI, Basel, Switzerland. This article is an open access article distributed under the terms and conditions of the Creative Commons Attribution license (http://creativecommons.org/licenses/by/3.0/). 